\title{
MODEL PENGUATAN KEARIFAN LOKAL DALAM MENJAGA KEAUTENTIKAN WISATA KULINER LOMANG DI KABUPATEN KUANTAN SINGINGI
}

\author{
Syafri Harto \\ Universitas Riau \\ e-mail: syafriharto@lecture.unri.ac.id
}

\begin{abstract}
The era of autonomy in the typical Kuantan Mudik culinary area does not develop like other regional foods, but the values of local wisdom still exist. For this reason, this research seeks to multiply the model of strengthening local wisdom in maintaining the authenticity of lomang culinary tours in the regency of singing and singing. The results of the study explain the drivers of strengthening local wisdom are the ability to maintain, preserve, and pass on local wisdom. Pewarisan local wisdom value is intended so that the younger generation of Kuantan Singingi Regency can protect itself from the negative effects of modernization due to globalization, but it becomes an idea for expressing and appreciating local wisdom values by empowering the community Kuantan Singingi District Government must include malomang activities as an event on the track runway event by utilizing a bottom-up system for millennials and communities that still maintain the Malomang tradition so that it becomes an attraction, with leverage like trees and crystallizes and fences like cages in lomang activities and marketing in tourist destinations.
\end{abstract}

Keywords: Termination. Local Wisdom, Empowerment

\begin{abstract}
Abstrak
Era otonomi daerah kuliner Khas Kuantan Mudik tidak juga berkembang-kembang seperti makan khas daerah lain, namun nilai-nilai kearifan lokalnya masih ada. Untuk itu dalam penelitian ini berusaha mengali model penguatan karifan lokal dalam menjaga keautentikan wisata kuliner lomang di kabupaten kuantan singingi.hasil penelitrian menjelaskan Faktor pendorong penguatan kearifan lokal adalah kemampuan dalam menjaga, melestari kan, dan mewariskan kearifan-kearifan lokal. Pewarisan nilai kearifan lokal dimaksudkan agar generasi muda Kabupaten Kuantan Singingi dapat memproteksi diri dari pengaruh negatif modernisasi akibat globalisasi, namun menjadi ide wahana ekspresi dan apresiasi terhadap nilai-nilai kearifan lokal dengan melakukan pemberdayaan masyarakat Pemerintah Kabupaten Kuantan Singingi harus memasukan kegiatan malomang sebagai event yang dilakukan pada event pacu jalur dengan memanfaatkan sistem bottom-up kepada masyarakat kaum milenial dan komunitas yang masih menjaga tradisi malomang sehingga menjadi daya tarik, dengan daya ungkit seperti pohon dan mengkristal dan memagar seperti sangkar dalam kegiatan dan pemasaran lomang di destinasi wisata
\end{abstract}

Kata Kunci : Keauntentikan. Kearifan Lokal, Pemberdayaan

\section{PENDAHULUAN}

Daya tari wisata saat ini yang sedang digalakan oleh Pemerintah untuk meningkatkan pendapatan nasional dan masyarakat selain destinasi pariwisata alam, atraksi, budaya juga dari kulinernya. Menurut (Syamsu:2001) yang membuat berhasilnya pariwisata dengan memenuhi faktor kelangkaaan yang alamiah dari segi budaya, faktor Keunikan sesuai ciri khas, faktor pemberdayaan masyarakat sesuai 
dengan potensi masyarakat, faktor optimalisasi lahan dan faktor pembangian yang merata bagi masyarakat.

Dalam penelitian ini akan memfokuskan pada pengembangan masyarakat secara Bottom-up dengan pendekatan pemberdayaan. Kegiatan pemberdayaan merupakan aspek yang akan mendorong terciptanya masyarakat yang sadar akan pariwisata yang akan melahirkan keramahtamaan, mempertahankan atraksi lama yang didukung oleh perubahan pola pikir komunitas dalam penggagas, perencana, pelaksana, dan pemantau dari kegiatan kepariwisataan yang dijalankan. Keterlibatan ini merupakan wadah bagi komunitas untuk berperan dalam pegambilan keputusan. Salah event pariwisata nasional yang berada di Kabupaten Kuantan Singingi adalah Pacu Jalur, namun kegiatan ini seakan-akan hanya kegiatan tahunan yang tidak memberikan dampak ekonomi kepada masyarakat tempatan. Seharusnya sektor kepariwisataan berbasis pemberdayaan masyarakat menimbulkan dampak positif pada lingkungan dan budaya lokal, dengan membantu meningkatkan pendapatan, pekerjaan, dan konservasi ekosistem setempat. Implementasi pariwisata berbasis komunitas, dimana konsep ini didukung oleh kegiatan antara lain adventure travel atau wisata petualangan, cultural travel atau wisata budaya, dan ecotourism atau wisata ekologi dapat mendorong peningkatan pendapatan dan minat para turis untuk mengenang adanya sesuatu yang didapat selain atraksi pacu jalur. Salah satu yang menjadi daya tarik turis data kepada kegiatan pariwisata adalah kulinernya, menurut Sari (2017) yang mempengaruhi wisatawan datang ke tujuan wisata adalah kuliner yang asli dan unik. Di Kabupaten Kuantan Singingi dalam melihat keunikan kuliner belum terlihat dalam program pemerintah menurut Syamartha (2015) yang menjadi masalah dalam kuliner khas Kuantan Singingi Kebersihan, dan kenaikan harga yang dilakukan oleh pedangang. Jadi dalam kenaikan pengunjung event pacu jalur semata-mata hanya melihat perlombaan saja, sehingga kuliner asli kuantan singingi tidak berkembang.

Berkaitan dengan pembangunan dari bawah (Botton-UP) dalam pengembangan kearifan lokal dalam wisata kuliner untuk mendukung event pacu jalur, peneliti mencoba menkonfigurasi teori pembangunan sosial dari bawah yang dipelopori oleh Billups (1990), Rubbin \& Babbie, Midgley (1993) dan David (1993) dengan menjadikan penguatan masyarakat berdasarkan kearifan lokal dengan adanya partisipasi masyarakat, pengembangan motivasi, kesempatan belajar, peneglolaan sumber daya lokal, Replikasi, Komunikasi, Lokalisasi Keuangan. Harapan dari penguatan kearifan lokal dengan model ini akan terjadi perubahan persepsi dalam meningkatkan taraf hidup, berorientasi kepada perilaku saat menghadapi wisatawan, dan meningkatkan standar hidup masyarakat.

Namun bertitik tolak dari terori ini sejalan dengan kuliner asli yang masih eksis di Kabupaten Kuantans Singingi salah satuya Lomang (Lemang) yang terbuat dari beras dan ubi kayu atau rambat yang dibungkus dengan bambu, namun keberadaannya bisa dijumpai saat hari pasar rabu di Teluk Kuantan dan Hari Minggu di Pasar Lubuk Jambi. Keberdaan kuliner ini memiliki keautentikan tersendiri dari daerah lain yang menjadi daya tarik ditingkat lokal.

Dari gambaran potensi pariwisata kabupaten Kuantan Singingi yang terdapat makanan tradisional khas Kecamtan Kuantan Mudik, Kecamtan Gunung Toar yang terbuat beras dan ubi. Kecamatan Kuantan Mudik dan Kecamatan Gunung Toar merupakan satu kecamatan yang telah dimekarkan yang masih mempunyai tradisi dan makan yang sama. Di Kecamatan Kuantan Mudik Lomang di buat selain untuk hari besar juga sudah dibuat untuk dijual di pasar teluk Kuantan dan Pasar Lubuk Jambi. Sedangkan sekarang di Kecamatan Gunung Toar lomang di buat hanya untuk hari besar seperti hari raya idul fitri. Lomang dipasarkan dalam bentuk matang di pasar. Lomang merupakan makanan tradisional khas Kabupaten Kuantan Singingi beras dan bisa dari ubi kayu atau rambat. Pada era perkembangan zaman yang semakin maju dan cepat, Lomang yang merupakan makanan tradisional tersebut sedianya dapat disulap dan diangkat menjadi makanan yang memiliki nilai jual lebih serta dapat dikemas lebih modern. Pengembangan makanan Lomang dengan cita rasa, warna, dan bentuk yang lebih modern tersebut dapat diwujudkan melalui banyak cara, salah satunya dengan penyelenggaraan suatu perlombaan kreasi 
makanan olahan Lomang, atraksi pembuatan namun demikian apa yang seharusnya menurut Zahrulianingdyah (2018) wisata kuliner baik skala nasional dan internasional akan terbuka apabila terdapat destinasi wisata yang berbasis kearifan lokal akan berdampak kepada ekonomi masyarakat sekitar, pendapatan asli daerah, income nasional, berkembangnya jajanan kuliner lokal sebagai buah tangan wisatawan yang bisa mengangkat citra pariwisata nasional. Hal ini bertolak belakang yang terjadi di Kabupaten Kuantan Singingi pada event pacu jalur yang sudah dilaksanakan sampai tahun 2018 sudah 115 Tahun, tetapi tidak menambah jajanan kuliner dan ekonomi masyarakat.

Wisata kuliner saat ini merupakan potensi yang menjajikan, karena makanan merupakan daya tarik tersendiri bagi wisatawan. Hal ini sebagai fungsi strategis bagi wisatawan untuk mengambil keputusan berkunjung kepada salah satu tempat destinasi wisata dan juga sebagai produk pariwisata dan promosi tempat wisata (Henderson, 2010).

Berdasarkan fenomena yang diamati peneliti selama era otonomi daerah kuliner Khas Kuantan Mudik tidak juga berkembang-kembang seperti makan khas daerah lain, namun nilai-nilai kearifan lokalnya masih ada. Untuk itu dalam penelitian ini berusaha mengali model penguatan karifan lokal dalam menjaga keautentikan wisata kuliner lomang di kabupaten kuantan singingi sehingga makanan ini akan terus berkembang dan menjadi mata pencarian yang meningkatkan pendapatan masyarakat tempatan.

\section{METODE}

\section{Jenis Penelitian}

Penelitian ini mengunakan jenis penelitian kualitatif dengan pendekatan etnografi karena penelitian ini berfokus pada kuliner yang berkaitan dengan budaya dan kearifan lokal selain itu peneliti sebagai instrumen sudah berpengalaman hidup bersama masyarakat yang dijadikan objek dan fokus penelitian.

\section{Teknik Pengumpulan Data}

Penelitian ini dalam mengumpulkan data mengunakan teknik Observasi, Wawancara dan Dokumentasi pada setiap kegiatan pengumpulan Data. Wawancara dilakukan kepada Pedagang Lomang, Tokoh Masyarakat Desa Rantau Sialang dan Stakeholders yang berkaitan dengan objek dan fokus penelitian.

\section{Jenis Data}

Data yang digunakan dalam penelitian ini Pertama adalah data Primer yang didapat langsung dari hasil observasi langsung dan Wawancara kepada informan penelitian. Kedua data Sekunder yang didapat melalui dokumentasi yang telah ada oleh lembaga maupun media cetak atau online maupun hasil kajian terdahulu tentang kearifan lokal dan kuliner di Kabupaten Kuantan Singingi.

\section{Lokasi Penelitian}

Penelitian ini agar terfokus dilakukan di daerah yang memproduksi lomang secara rutin baik hari besar dan pasar yaitu di Kecamatan Kuantan Mudik Desa Rantau Sialang, pemilihan lokasi ini berdasarkan titik permasalahan dan sesuai dengan keautentikan lomang yang masih terjaga.

\section{Analisis Data}

Analisis data yang digunakan adalah dengan Model Interaktif menurut Miles Huberman (1994) : 


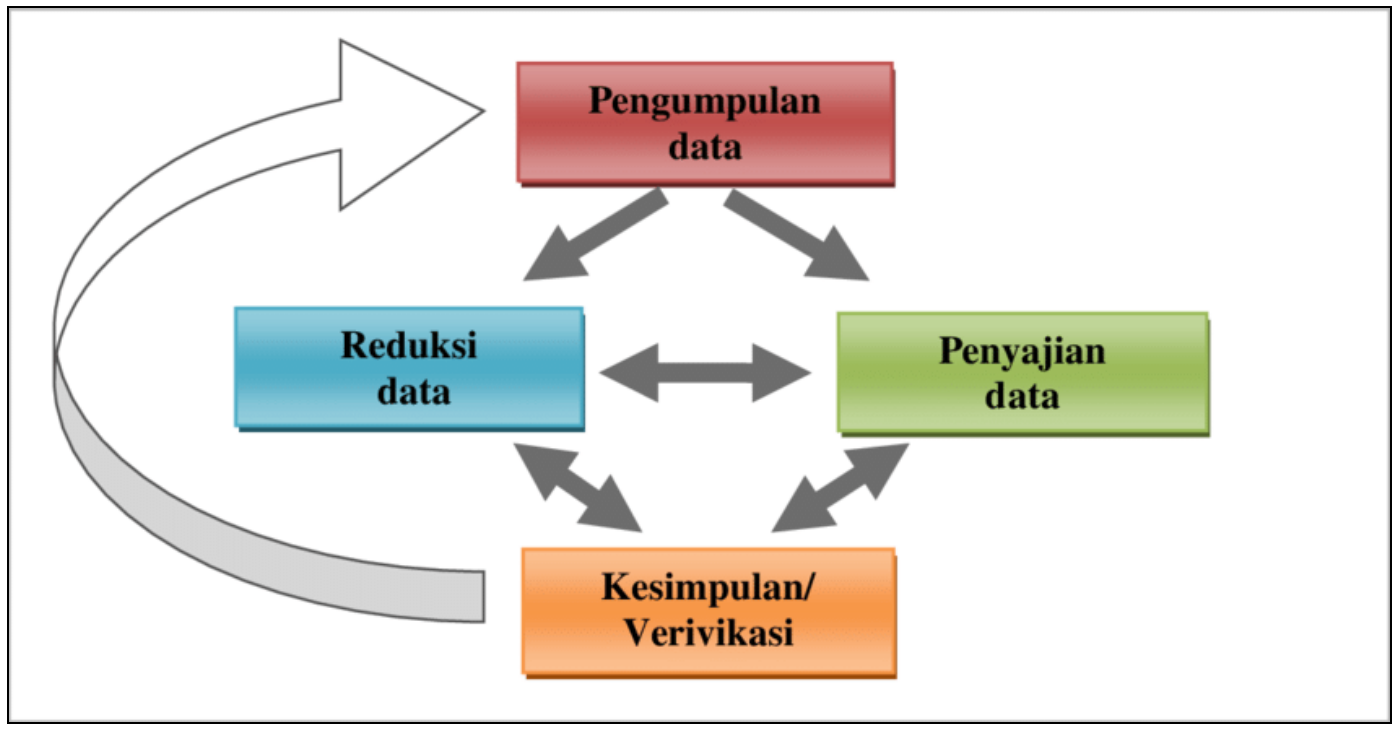

\section{HASIL DAN PEMBAHASAN}

Pemberdayaan masyarakat dalam pengembangan wisata kuliner sangat urgency karena akan mendorong masyarakat sadar akan kegiatan pariwisata sehingga akan berdampak kepada keramahtamahan, kepedulian, peningkatan ekonomi masyarakat. Pemberdayaan berdasarkan kearifan lokal dalam wisata kuliner mempunyai daya tarik tersendiri, karena dalam pembuatan Lomang (Lemang) ada kegiatan yang dilakukan secara tradisonal akan menambah daya tarik, dengan atraksi proses pembuatannya dengan pembakaran secara bersama oleh para perempuan dan para lelaki mencari kayu dan kulit kelapa dalam proses memasaknya.

Berdasarkan hasil wawancara dengan pembuat Lomang," dulu kegiatan pembuatan lomang dilakukan dengan secara tradisonal mulai dari pencarian bambu, sampai proses memasak dilakukan secara bersama, namun hari ini dibuat sesuai tersendiri". Sementara itu para kaum perempuan, mempersiapkan beras pulut, mulai dari merendam, membuat santan, mencari daun pisang untuk dimasukkan kedalam bambu dan kemudian diisi dengan beras pulut untuk selanjutnya dimasak dengan cara dipasang didekat bara api yang dijaga panasnya agar lemang tidak hangus. Menurut Informan saat menunggu lemang masak di perapian bara api, salah satu momen keasikan tersendiri karena sambil menunggu lemang masak, sambil bercengkerama dengan keluarga, hal ini menambah semaraknya suasana menjelang hari raya di desa-desa.

Potensi Lomang ini di Kabupaten Kuantan Singingi sebagai keraifan lokal dan potensi kuliner cukup berpengaruh bagi wisatawan, ini terungkap dari naiknya harga kuliner di Kabupaten Kuantan Singingi pada saat event Pacu Jalur, harga sebelum kegiatan pacu jalur Rp. 15.000- Rp. 20.000 dan saat event Pacu Jalur Rp. 25.000-35.000 (Sumber Dinas Pariwisata Kab. Kuantan Singingi). Kearifan lokal menjadi penting dalam mempertahankan karakter, untuk melindungi tradisi, untuk mengatasi krisis identitas kelompok (Efendi,2004). Potensi kegiatan malomang seharusnya menjadi dijadikan sebagai kegiatan memperkuat kearifan lokal, karena adanya kerjasama dan tradisi yang masih melekat. Namun kegiatan malomang di desa Rantau Sialang tinggal beberapa kepala keluarga yang masih menjaga tradisi dan potensi ekonomi keluarga karena lomang bagi wisatawan cukup berpengaruh harganya dalam event pacu jalur.

Kearifan lokal yang dimaksud adalah pemikiran atau ide setempat (lokal) terdapat nilai-nilai bijaksana, kreatif, kebaikan, yang terinternalisasi secara turun temurun (mentradisi). Nilai-nilai tersebut 
dipercaya mengandung kebenaran sehingga diikuti oleh anggota masyarakatnya, kearifan lokal ini yang bisa disebut nilai-nilai luhur (adhiluhung) masyarakat yang berfungsi sebagai landasan filsafat perilaku yang baik menuju harmonisasi (Kriyantoro, 2014). Dalam memperkuat kearifan lokal dalam keautentikan Lomang sebagai destinasi kuliner pendukung event pacu jalur, peneliti juga mengkonfigurasi teori Cheng (2005) bahwa dalam memperkuat kearifan lokal dengan menjadikan mengakar seperti pohon kepada generasi muda. Harapannya individu yang berpikir globalisasi bertindak secara lokal, maknanya kegiatan ini membudaya ditingkat lokal sehingga berpengaruh secara global. Selanjutnya Kristal budaya dengan bertindak secara global untuk berpikir secara lokal. Dan yang ketiga Sangkar burung yang mendorong terhadap keterbukaan budaya luar yang dibatasi dengan kerangka kerja lokal.

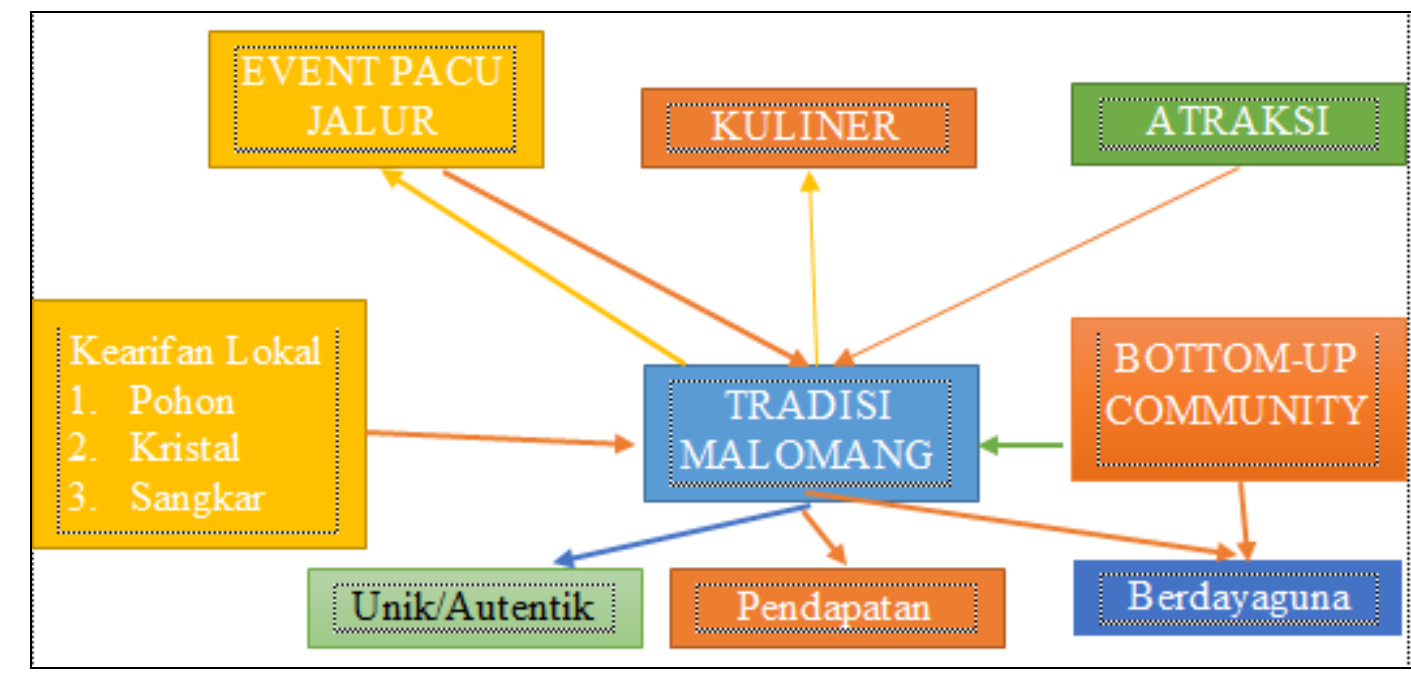

\section{Gambar Model Penguatan Kearifan Lokal Keauntetikan Lomang Wisata Kuliner di Kabupaten Kuantan Singingi.}

Pada tahap penguatan Kearifan lokal keautentikan Kuliner Lomang sebagai daya dukung event pacu jalur di Kabupaten Kuantan Singingi terdapat tiga daya ungkit untuk yang digunakan dengan teori pohon, kristal dan sangkar yang dikemukan oleh Seng, auputnya dapat dilihat dari tradisi Malomang adalah terciptakanya keunikan/autentik lomang dari daerah lain yang menjadi cita rasa yang disukai setiap pengunjung, selanjutnya kan meningkatkan pendapatan bagi masyarakat dan pemerintah daerah dengan mendayagunakan komunitas yang masih menjalankan profesi sebagai pedagang lomang. Daya ungkit bisa dijalankan dengan mengedepankan lomang sebagai ikon kuliner sebagai daya dukung event pacu jalur dan diadakan atraksi proses produksinya secara modrn dengan seni tanpa menghilangkan keaslian cita rasa dan tradisi melomang.

Tradisi malomang ini dapat dikaji lebih lanjut dalam meninggkatkan nilai seni budaya sekaligus nilai-nilai ekonomi dengan memberikan sentuhan ahli gizi pangan untuk meningkatkan kualitas produk makanan yang dihasilkan. Mengkonsumsi produk makanan merupakan representasi dari salah satu kegiatan yang menyenangkan dan dipertimbangkan dalam mengunjungi sebuah negara (Frochot, 2003). Bahkan dalam penelitiannya Saleh (2012) menyebutkan bahwa kenyataannya wisatawan akan menjadikan pengurangan budget untuk aktivitas sebagai alternatif terakhir temuannya satu pertiga budget wisatawan digunakan untuk mengkonsumsi produk kuliner.

Kegiatan malomang ini merupakan sektor kuliner yang memiliki peluang yang cukup baik bagi sektor pariwisata secara global, dimana pengembangan wisata kuliner akan dapat meningkatkan minat pengunjung dan meningkatkan pendapatan dari sektor pariwisata, sehingga membangun sebuah produk kuliner merupakan bagian yang penting dalam membangun pariwisata secara keseluruhan. Pada atraksi 
tradisi malomang dapat dikembangkan aktivitas kesenian yang dilakukan dengan sentuhan manajemen seni yang berimplikasi pada pertunjukan seni yang ditampilkan menjadi suatu tontonan seni yang bernilai seni budaya sekaligus menghibur penontonnya. Tahap penguatan memberikan ruang untuk meningkatkan kualitas aktivitas budaya lokal dengan memberikan perhatian pada segi sumber daya manusia, prasarana, regenerasi, motivasi aktor-aktor pelaksana yang terlibat. Pada tahapan ini pemanfaatan teknologi komunikasi dan informasi dapat dilakukan dalam kerangka perluasan dan percepatan informasi adanya aktivitas budaya kearifan lokal di Kabupaten Kuantan Singingi.

\section{KESIMPULAN}

Faktor pendorong penguatan kearifan lokal adalah kemampuan dalam menjaga, melestari kan, dan mewariskan kearifan-kearifan lokal. Pewarisan nilai kearifan lokal dimaksudkan agar generasi muda Kabupaten Kuantan Singingi dapat memproteksi diri dari pengaruh negatif modernisasi akibat globalisasi, namun menjadi ide wahana ekspresi dan apresiasi terhadap nilai-nilai kearifan lokal dengan melakukan pemberdayaan masyarakat komunitas lomang dengan memnfaat budaya globalisasi dengan pemikiran lokal.

\section{KESIMPULAN}

Pemerintah Kabupaten Kuantan Singingi harus memasukan kegiatan malomang sebagai event yang dilakukan pada event pacu jalur dengan memanfaatkan sistem bottom-up kepada masyarakat kaum milenial dan komunitas yang masih menjaga tradisi malomang sehingga menjadi daya tarik, dengan daya ungkit seperti pohon dan mengkristal dan memagar seperti sangkar dalam kegiatan dan pemasaran lomang di destinasi wisata Kabupaten Kuantan Singingi

\section{DAFTAR PUSTAKA}

[1]. Billups, J.O. (1990) Toward Social Development as an Organizing Concept For Social Work and Related Social Professions and Movements. Social Development Issues. (j2 (3), 14-26.

[2]. Cheng, Y. C. (2005). Fostering local knowledge and human development in globalization of education. New Paradigm for Re-engineering Education: Globalization, Localization and Individualization, 73-94.

[3]. David, G (1993) Strategies for Grass roots human development. Social Development Issues 15 (2) 113.

[4]. Effendi, Tengku (2004) Tunjuk Ajar Melayu (Butir-Butir Budaya Melayu Riau. Yogyakarta;Adicita Karya.

[5]. Fajarini, U. (2014). Peranan kearifan lokal dalam pendidikan karakter. SOSIO-DIDAKTIKA: Social Science Education Journal, 1(2), 123-130. 
[6]. Frochot, I. (2003). An analysis of regional positioning and its associated food images in French tourism regional brochures. Journal of Travel \& Tourism Marketing, 14(3-4), 77-96.

[7]. Henderson, J.C. (2010). Sharia-compliant hotel. Tourism and Hospitality Research 10(3), 246-254. DOI: http://dx.doi.org/10.1057/thr.2010.3.

[8]. J. C. Henderson, “Food tourism reviewed,” Br. Food J., vol. 111, no. 4, pp. 317-326, 2009

[9]. Kriyantono, Rachmat (2014).Teori Public Relations Perspektif Barat Dan Lokal: Aplikasi Penelitian dan Praktik. Jakarta: Kencana.

[10]. Miles, M. B., Huberman, A. M., Huberman, M. A., \& Huberman, M. (1994). Qualitative data analysis: An expanded sourcebook. sage.

[11]. Midgley, J. (1992) Development Theory, The State and Social Development in Asia. Social Development Issues, 14 (1) 71-82

[12]. Rubin, A\& Babbie, E. (1993) Research Methods For Social Work (2 ${ }^{\text {nd }}$ ed.) Pacifik Grove, California; Brooks/Cole Publishing Company.

[13]. Sari, H. P. R. (2017). Analisis keautentikan dan keunikan laksa cihideung sebagai kuliner unggulan kota bogor. Transparansi Jurnal Ilmiah Ilmu Administrasi, 9(2), 255-269.

[14]. Syamartha, O., \& Sidiq, S. S. (2015). Persepsi wisatawan terhadap penetapan harga kuliner pada event pacu jalur di kabupaten kuantan singingi. Jurnal Online Mahasiswa (JOM) Bidang Ilmu Sosial dan Ilmu Politik, 2(2), 1-12.

[15]. Syamsu dkk. 2001. "Penerapan Etika Perencanaan pada kawasan wisata, studi kasus di kawasan Agrowisata Salak Pondoh, Kabupaten Sleman, Daerah Istimewa Yogyakarta". Jakarta: LP3M STP Tri Sakti, Jurnal Ilmiah, Vol 5. No. 3 Maret 2001.

[16]. Zahrulianingdyah, A. (2018). Kuliner Sebagai Pendukung Industri Pariwisata Berbasis Kearifan Lokal. Teknobuga, 6(1), 1-9 